www.jmscr.igmpublication.org

Impact Factor 3.79

Index Copernicus Value: 5.88

ISSN (e)-2347-176x ISSN (p) 2455-0450

crossref DOI: _http://dx.doi.org/10.18535/jmscr/v3i12.24

Journal Of Medical Science And Clinical Research

\title{
Spectrum of Disorders Diagnosed By Bone Marrow Aspiration in Pediatric Population
}

\author{
Authors \\ Dr Aparajita Tomar1, Dr RPS Chauhan², Dr R.K. Nigam \\ ${ }^{1}$ Assistant Professor, Department of Pathology, Bundelkhand Medical College, Sagar, MP, India, 470001 \\ ${ }^{2}$ Medical Officer, District Hospital, Sagar, Madhya Pradesh, India \\ ${ }^{3}$ Professor, Department of Pathology, Gandhi Medical College, Bhopal, Madhya Pradesh, India \\ Corresponding Author \\ Dr Aparajita Tomar
}

MBBS, MD, Pathology, Dept of Pathology, Bundelkhand Medical College, Sagar, Madhya Pradesh, India E-mail: draparajitatomar@gmail.com, Tel: 090396-32272 Fax: 07582-236270

\begin{abstract}
AIMS AND OBJECTIVES - To identify and analyse the most common hematological disorders diagnosed by doing bone marrow aspiration in pediatric patients.

MATERIAL AND METHOD - Bone marrow aspiration was done from Manubrium of the Sternum after injecting $2 \%$ xylocaine to the part in addition to sedation with diazepam. Bone marrow smears were prepared and stained with Leishman stain along with the simultaneous staining of the peripheral smears. A complete hemogram including $\mathrm{Hb} \%, \mathrm{PCV}$, Red cell indices, platelet count, total leucocyte count and differential leucocyte count was also done by Automated cell counter. Finally, the bone marrow and peripheral smears were examined manually under oil immersion.

CONCLUSION - In this study it was found that the most frequently diagnosed hematological disorders on bone marrow aspiration in children are Anemias followed by Idiopathic Thrombocytopenic Purpura (ITP). Hematological disorders are more common in childhood period as compared to late adulthood. If taken individually then ITP cases outnumber the Anemia cases. Commonest leukemia in children is Acute Lymphoblastic Leukemia (ALL) and it follows the Anemias and ITP.

KEYWORDS: Bone Marrow Aspiration, Anemia, Leukemia, Idiopathic Thrombocytopenic Purpura.
\end{abstract}

\section{MATERIAL AND METHOD}

Study area and design - The present study was done in the Department of pathology, Gandhi Medical College and associated Hamidia hospital, Bhopal M.P. A total of 32 consecutive prospective cases(children under the age of 14 years) were studied during a span of one year.

Ethical consideration - Bone marrow aspiration was done under all aseptic precautions and samples were processed according to the established laboratory protocol before generating final report to the patient. Informed consent regarding the procedure was taken from the guardian of the child prior to the aspiration. It was told to the guardians of the children that the information shared by them and the results thereafter will be used for medical research. 
Patient's Selection criteria - Our study included all the pediatric patients under the age of 14 years who were admitted in Hamidia hospital with a clinical suspicion of hematological disorder and were demonstrating some abnormality in the peripheral blood smears. OPD patients on clinical suspicion of a hematological disorder by the consultant incharge (pediatrician incharge) were also included in the study group after obtaining the detailed history, clinical examination and all relevant investigations. Children with highly increased bleeding time and clotting time were deterred.

\section{PROCEDURE}

\section{BONE MARROW ASPIRATION}

Child's attendants were told about the entire procedure and a written consent was taken. Complete patient preparation (xylocaine sensitivity testing, cleaning and draping) was done prior to the bone marrow aspiration. The skin over the sternum was cleaned with $70 \%$ ethyl alcohol. The skin, subcutaneous tissue and the periosteum overlying the manubrium was infiltrated with $1-1.5 \mathrm{ml}$ of $2 \%$ xylocaine. Two minutes were given to achieve the effect of anaesthesia and sedation with diazepam was used. The site of puncture of the manubrium was opposite to the second intercostals space and slightly to one side of the midline.

The guard on the aspiration needle was adjusted and with the boring movement, needle (salah needle) was passed perpendicularly into the cavity. After piercing the skin and the subcutaneous tissue when the needle point reached the periosteum, the needle was pushed with a boring motion into the cavity and the termination point as achieved when there was loss of resistance. Stilette was removed and a $10 \mathrm{ml}$ dispovan syringe was attached to the needle to suck the marrow contents. Not more than $0.3 \mathrm{ml}$ of marrow fluid was sucked in a single aspiration.
Immediately, 6-8 good marrow smears were made and dried quickly with the help of a hair drier. Simultaneously, 2-3 peripheral blood smears were also made. The slides were numbered with a diamond pencil. Two marrow smears and one peripheral blood smear were taken for leishman staining while the rest of the unstained smears, after being fixed in methanol were wrapped in an aluminium foil and kept in a dry place for future use.

\section{LEISHMAN STAINING OF SLIDES}

Bone marrow smears and the peripheral blood smear were placed on a staining rack and leishman stain was put drop by drop on the film so as to cover it completely. After 2 minutes, double the volume of buffered water was added and the two were mixed together with the help of a dropper. After 20 minutes, slides of peripheral smear were washed under the running tap water and the scum was drained off while bone marrow smears were washed after 30 minutes. Back side of the slides was wiped off with a clean and dry filter paper. The slides were kept in a vertical position to drain and dry. The slides were now ready for the microscopic examination.

\section{REPORTING OF BONE MARROW SMEARS}

Bone marrow as well as peripheral smears were first scanned with 4X lens followed by the examination under low power (10X), high power (40X) and oil immersion lenses (100X) respectively. The final reports were dispatched in the prescribed format only. 
OBSERVATION AND DISCUSSION

TABLE No. 1 SPECTRUM OF DISORDERS IN PEDIATRIC AGE GROUP

\begin{tabular}{|l|l|c|c|}
\hline S.No. & \multicolumn{1}{|c|}{ DISORDER } & TOTAL & PERCENTAGE \\
\hline 1 & ITP & 08 & 25 \\
\hline 2 & Megaloblastic Anemia & 07 & 21.9 \\
\hline 3 & Hypoplastic Marrow & 05 & 15.7 \\
\hline 4 & ALL & 04 & 12.5 \\
\hline 5 & Dimorphic Anemia & 03 & 9.4 \\
\hline 6 & AML & 03 & 9.4 \\
\hline 7 & Hypersplenism & 01 & 3.1 \\
\hline 8 & Leishmaniasis & 01 & 3.1 \\
\hline & Total & 32 & 100.0 \\
\hline
\end{tabular}

\section{SPECTRUM OF DISORDERS IN PEDIATRIC AGE GROUP}

\section{Leishmaniasis \\ $3 \%$}

Hypersplenism

$3 \%$

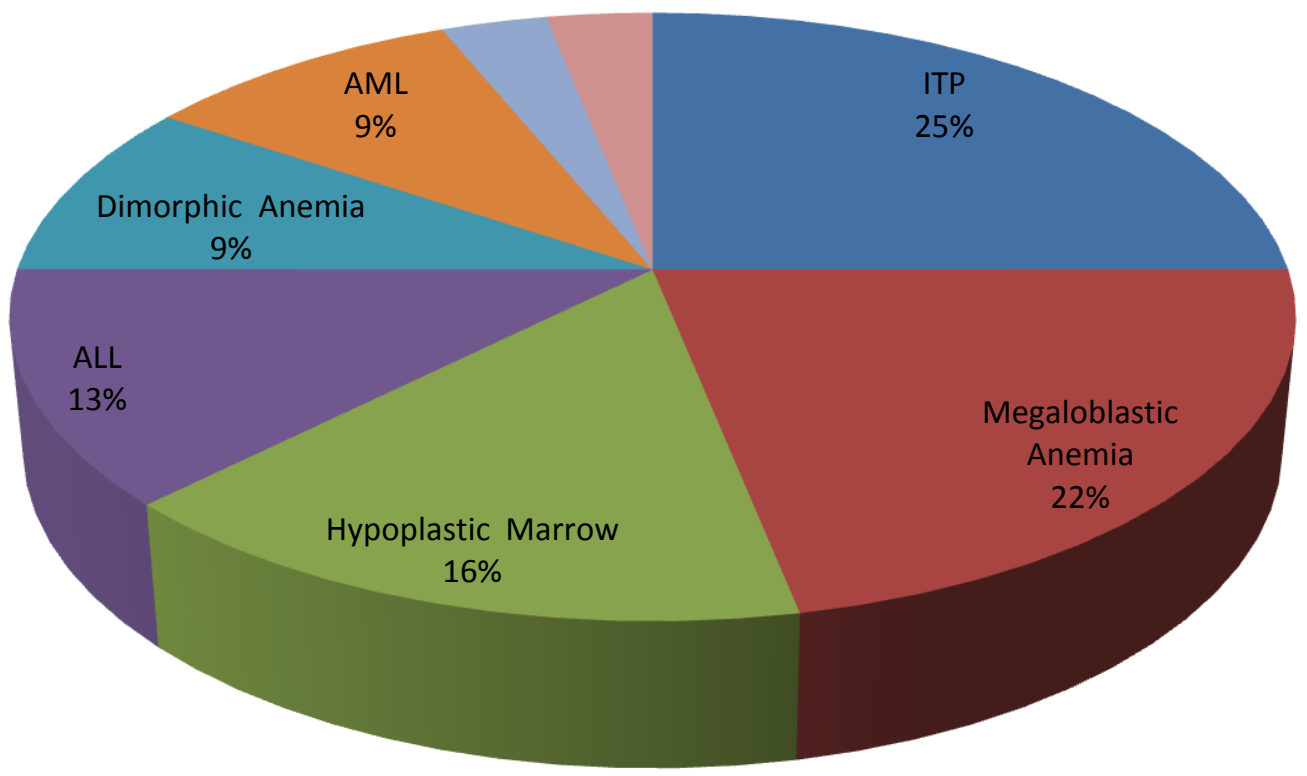

TABLE No. 2 PERCENTAGE OF CASES IN PEDIATRIC AGE GROUP, EARLY ADULTHOOD, LATE ADULTHOOD AND IN OLD AGE

\begin{tabular}{|l|c|}
\hline AGE (Yrs) & PERCENTAGE \\
\hline $0-20$ & 41.5 \\
\hline $21-40$ & 33.3 \\
\hline $41-60$ & 22.2 \\
\hline$>60$ & 3.0 \\
\hline
\end{tabular}




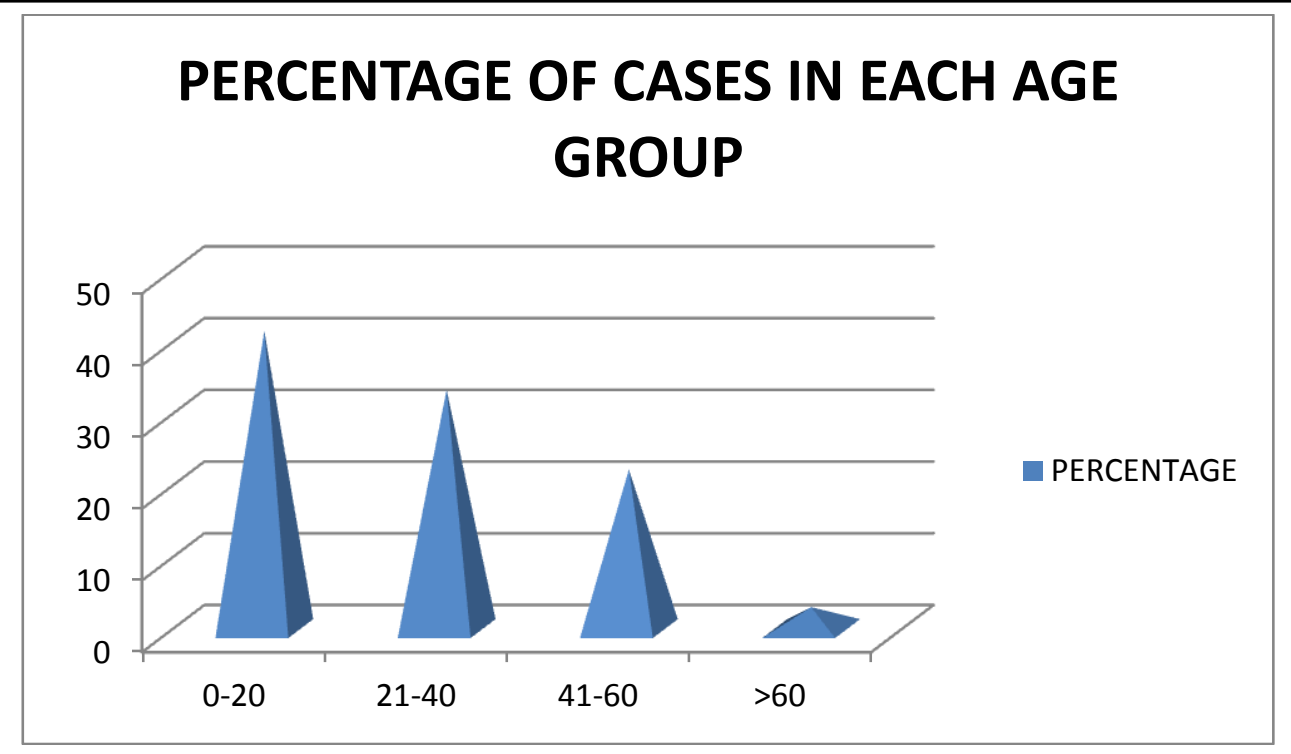

Table No. 3 GENDER DISTRIBUTION IN PEDIATRIC POPULATION AND IN ADULTS

\begin{tabular}{|l|c|c|}
\hline AGE(Yrs) & MALES(\%) & FEMALES(\%) \\
\hline $0-20$ & 57.1 & 42.9 \\
\hline $21-40$ & 53.3 & 46.7 \\
\hline $41-60$ & 70 & 30 \\
\hline$>60$ & 25 & 75 \\
\hline
\end{tabular}

\section{GENDER DISTRIBUTION}

$\square$ MALES $\square$ FEMALES

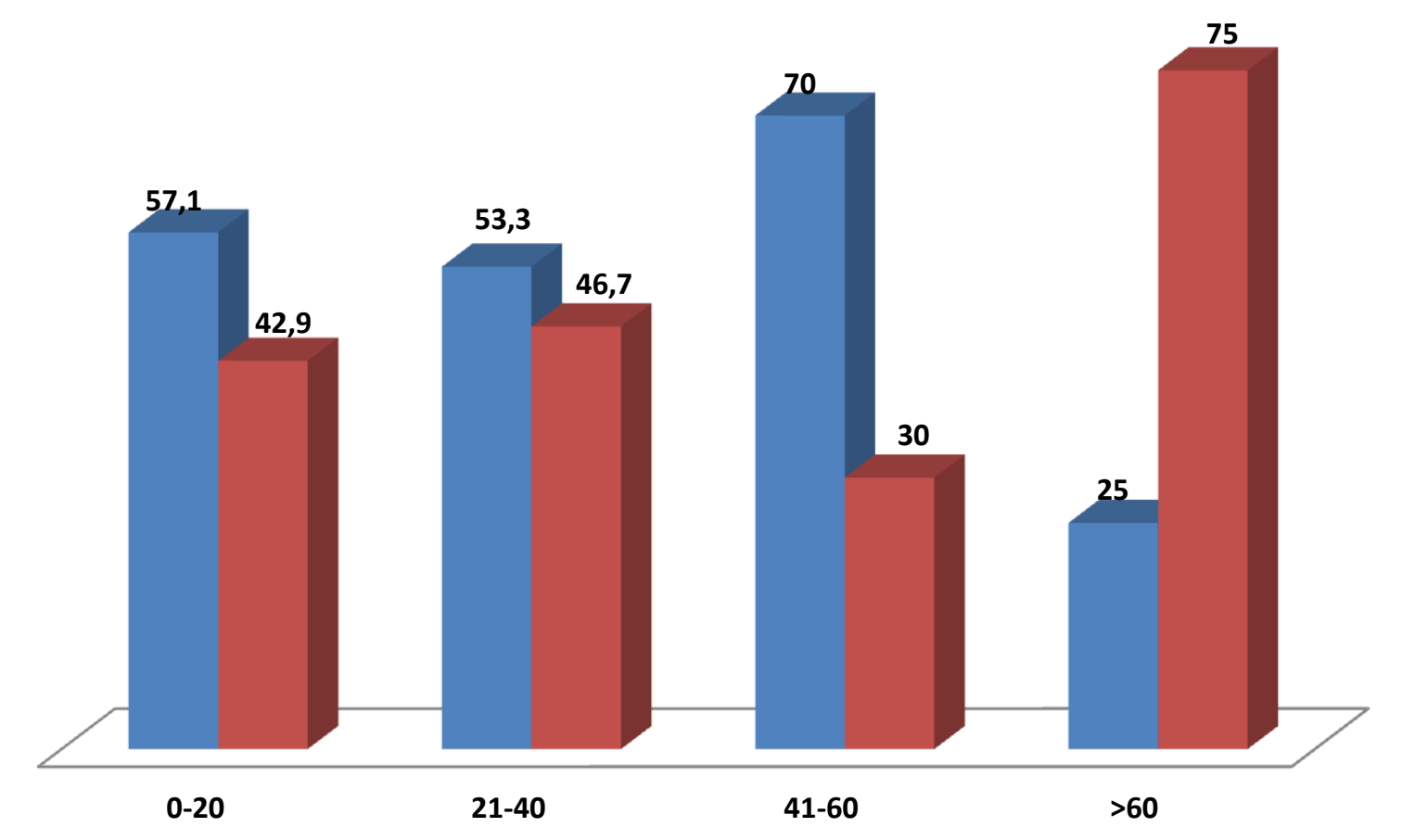


TABLE NO. 4 AGE WISE DISTRIBUTION OF CASES OF ITP

\begin{tabular}{|l|c|}
\hline $\begin{array}{l}\text { AGE } \\
\text { RANGE(YRS) }\end{array}$ & ITP CASES IN PERCENTAGE \\
\hline $0-10$ & 53.8 \\
\hline $11-20$ & 30.8 \\
\hline $21-30$ & 7.7 \\
\hline $31-40$ & 7.7 \\
\hline
\end{tabular}

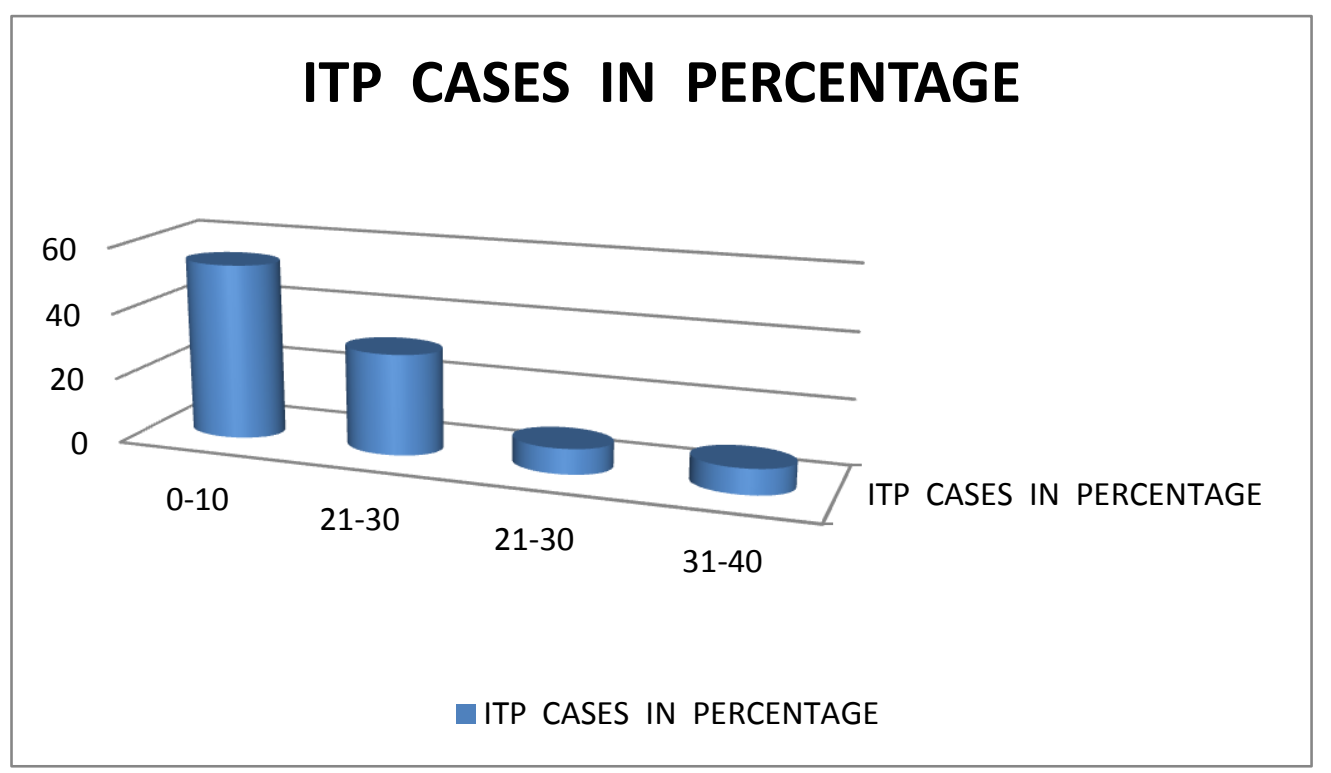

TABLE NO. 5 LEUKEMIA INCIDENCE IN ADULTS AND CHILDREN

\begin{tabular}{|l|c|c|}
\hline LEUKEMIA & ADULTS & CHILDREN \\
\hline AML & 76.9 & 23.1 \\
\hline ALL & 55.5 & 44.4 \\
\hline CLL & 100.0 & 0.0 \\
\hline
\end{tabular}

\section{LEUKEMIA INCIDENCE IN ADULTS AND CHILDREN (IN PERCENTAGE)}

$\because$ ADULTS $\square$ CHILDREN

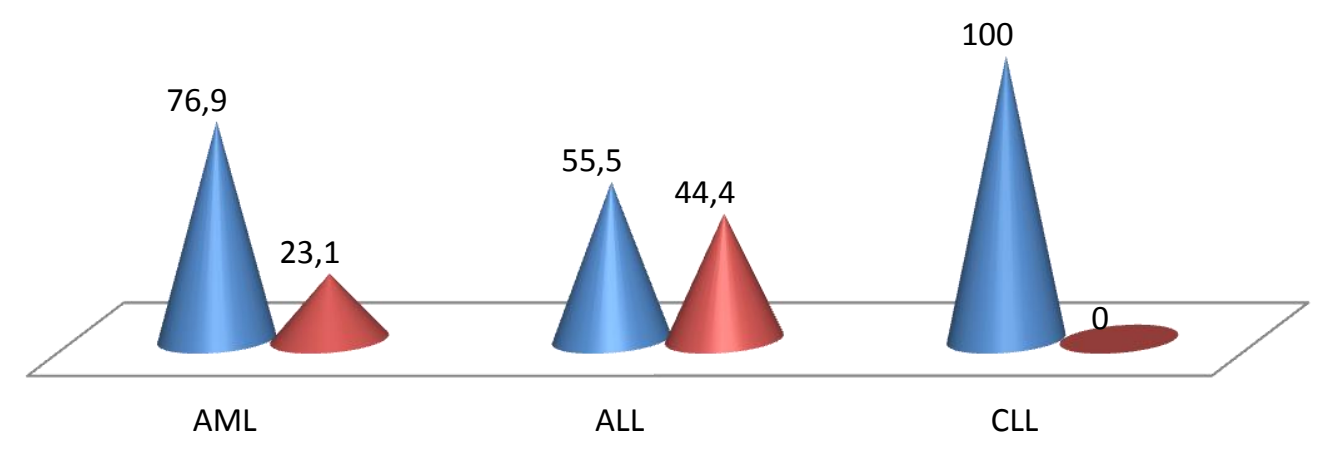




\section{CONCLUSION}

In our study of 32 pediatric cases, we concluded that the most frequently encountered hematological disorder on bone marrow ${ }^{4}$ examination $^{3}$ in children under the age of 14 years is Anemia as a whole followed by ITP $^{1,2,5,7,9,11}$. If considered individually, then ITP cases outnumber the anemia cases and the most commonly occurring anemia subtype in children is Megaloblastic ${ }^{8,10}$ anemia. Hypoplastic Marrow ranks third in the list followed by Acute Lymphoblastic Leukemias ${ }^{6}$. Hematological disorders are more common in childhood period as compared to late adulthood. Overall prevalence of leukemias is less in children as compared to adults. Maximum number of patients of ITP are children below the age of 10 years who presented most commonly as bleeding from skin and mucous membranes with epistaxis being the commonest presentation followed by petechiae. Patients with Hypoplastic Marrow presented clinically as pallor, fever and bleeding from various sites. Megaloblastic anemia and ALL patients presented clinically as pallor and fatigue and pallor and fever respectively.

\section{ACKNOWLEDGEMENT}

Smt. Annapurna Tomar, Dr. R.K Nigam and the entire staff of the department of pathology, Gandhi Medical College, Bhopal, M.P.

\section{REFERENCES}

1. Ahmad Z, Durrani NU, Hazir T. Bone marrow examination in ITP in children : is it mandatory? J Coll Physicians Surg Pak. 2007 Jun; 17(6): 347-9.

2. Calpin C, Dick P,Poon A, Feldman W. Is bone marrow aspiration needed in acute childhood idiopathic thrombocytopenic purpura to rule out leukemia? Arch pediatr Adolesc med. 1998 Apr; 152(4): 345-7.
3. Githang J.N. and Dave P. Bone marrow examination at a pediatric hospital in Kenya. East Africa Medical Journal Vol. 78 No. 7(supplement) July 2001.

4. Glaser K, Limarzi L and Poncher HG (1950). Cellular composition of the bone marrow in normal infants and children. Pediatrics, 6, 789-824.

5. Halperin DS, Doyle JJ. Is bone marrow examination justified in idiopathic thrombocytopenic purpura? Am J Dis Child. 1998 May ; 142(5): 508-11.

6. Idris M, Shah SH, Fareed J, Gul N. An experience with 60 cases of hematologyical malignancies; a clinico haematological correlation. J Ayub Med Coll Abbottabad 2004 Oct-Dec; 16(4): 51-4.

7. Jubelirer SJ, Harpold R. The role of the bone marrow examination in the diagnosis of immune thrombocytopenic purpura: case series and literature review. Clin Appl Thromb Hemost. 2002 Jan ;8 (1):73-6.

8. Mercedes V, VDA. DE Torregrosa, Margarita Caceres De Costas. Megaloblastic anemia of infancy. Clinical Pediatrics, Vol. 3, No. 6, 348-354 (1964).

9. Muhury Manas, Alka M Mathai, Sharada Rai, Ramadas Naik, Muktha R Pai, Ruchi Sinha. Megakaryocytic alterations in thrombocytopenia: A bone marrow aspiration study. Indian Journal of Pathology and Microbiology. Year: 2009, Vol: 52, Issue: 4, Page : 490-494.

10. Tariq Ayub and Fazal ur Rahman Khan. Prevalence of megaloblastic anemia in a pediatric unit. Gomal Journal of Medical Sciences ; JanuaryJune 2009, Vol. 7, No. 1:62-4.

11. Wong G C, Lee L H. A study of idiopathic thrombocytopenic purpura (ITP) patients over a ten year period. Ann Acad Med Singapore 1998; 27: 789-93. 